\title{
A tailings beach slope model featuring plug flow
}

\author{
T.G. Fitton ATC Williams Pty Ltd, Australia \\ P.T. Slatter ATC Williams Pty Ltd, Australia
}

\begin{abstract}
It has been observed that plug flow can occur in the open channels that naturally form on a tailings beach if the tailings slurry is sufficiently thickened. Plug flow occurs when a yield stress fluid develops an unsheared zone (or plug) in the centre of a channel, pipe or other conduit. It is caused when the yield stress of the slurry is greater than the shear stresses that are acting on it.
\end{abstract}

This paper presents a new tailings beach slope prediction model that incorporates a plug flow model. The beach slope model is validated using flume data from Chuquicamata, Sunrise Dam and Peak Gold Mine, as well as a range of full scale beach data from some 29 real tailings beaches. It has been found that reasonably accurate predictions are achieved.

\section{Introduction}

Tailings beaches are typically concave in profile (Melent'ev et al., 1973). Such beaches are formed in an alluvial process, in which tailings slurry flows in meandering channels over previously deposited tailings, ultimately conveying fresh tailings to a point on the beach that is flatter than the channel is capable of maintaining. At this point channel flow ceases and sheet flow begins. It is the sheet flow that yields new tailings deposition, but the channel flow that dictates the beach slopes found on the deposit (Williams and Meynink, 1986; Pirouz et al., 2005; Chryss et al., 2006; Fitton et al., 2006).

It has previously been proposed that the slurry that flows in channels down tailings beaches must do so in the turbulent regime (Fitton et al., 2006). This theory was based on observations made on a number of tailings beaches where the tailings slurry had been thickened to a moderate degree. It has more recently been observed that plug flow occurs in such channels if the tailings slurry is thickened to a greater degree, such that it possesses a yield stress $\left(\tau_{y}\right)$ that exceeds the shear stresses that are active in the channel. In a plug flow regime, an unsheared core of a yield stress fluid is conveyed in the centre of the flow, with a sheared zone formed around it to carry it. It is currently thought that this sheared zone consists only of laminar flow, with no turbulence (Slatter, 1997). A laminar plug flow model has been presented for pipes (Slatter, 1997), but no such work is known to have been carried out for open channels.

This paper presents a new tailings beach slope model, as well as a new plug flow model. The plug flow model provides the beach slope model with a theoretical basis for it to predict beach slopes that result from the discharge of highly thickened tailings slurry that exhibits high yield stress values.

\section{$2 \quad$ An open channel plug flow model}

The channels that flow on tailings beaches are self-formed, with deposited tailings forming the channel bed and banks. Little is known about the cross sectional shape of such channels. Chryss et al. (2006) presented some measured cross sections of such channels, and then went on to present a theoretical model based on river modelling that predicted a self-formed tailings channel cross section using a complex vector addition method. Fitton (2007) had assumed a parabolic cross section in his efforts to model tailings channels, since such geometry was simpler to mathematically analyse.

In this current work an ellipse is assumed instead of the parabola. It is argued that half an ellipse is a more realistic cross sectional shape for a self-formed channel, particularly at the banks of the channel, where the sharp points of the parabola are deemed to be unrealistic compared to the vertical up-turns of the ellipse. 
A diagram illustrating plug flow in an elliptical self-formed channel is presented as Figure 1. Diagrams are presented in Figure 2 to show the distribution of shear stress and velocity in pipe and channel centrelines in laminar flow, highlighting the impact of yield stress fluids.

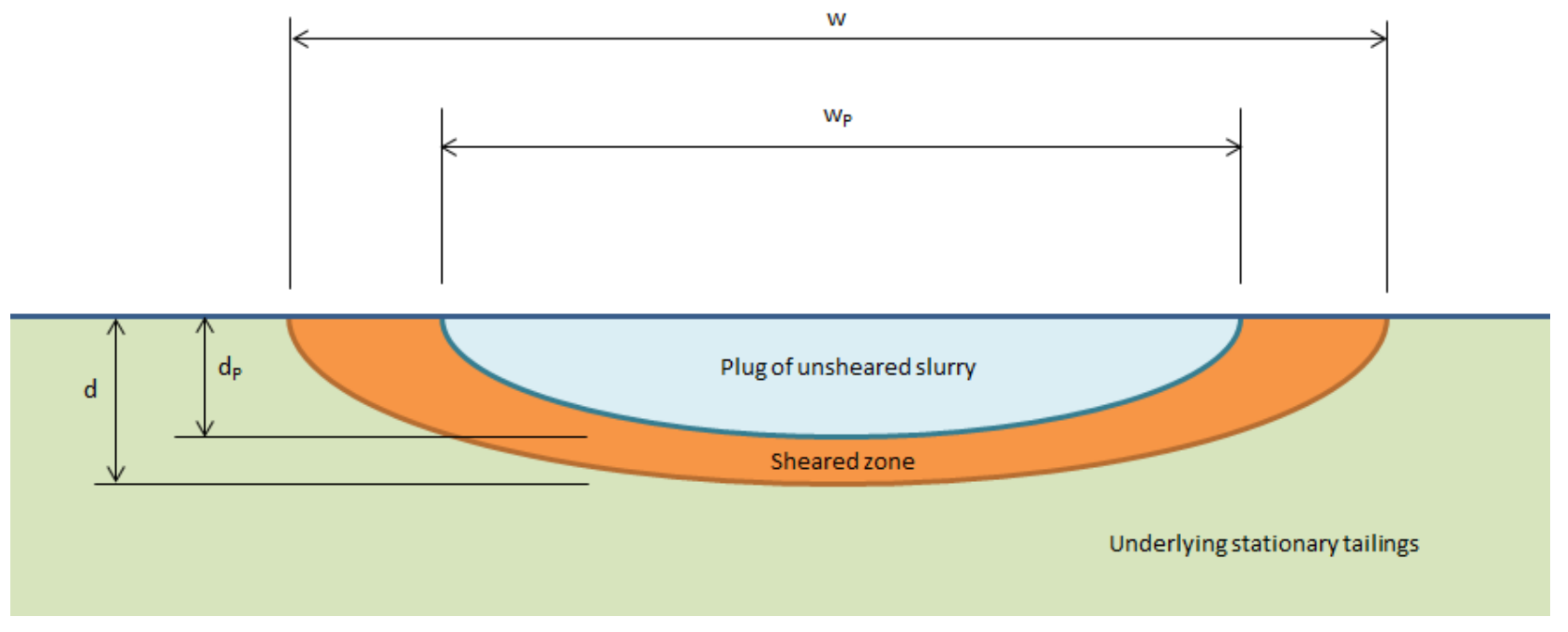

Figure 1 Open channel plug flow observed in tailings

\section{LAMINAR PIPE FLOW}

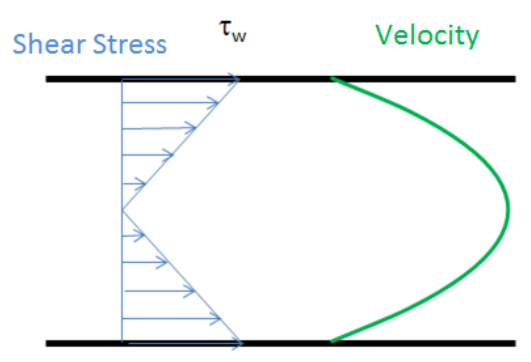

Newtonian fluid

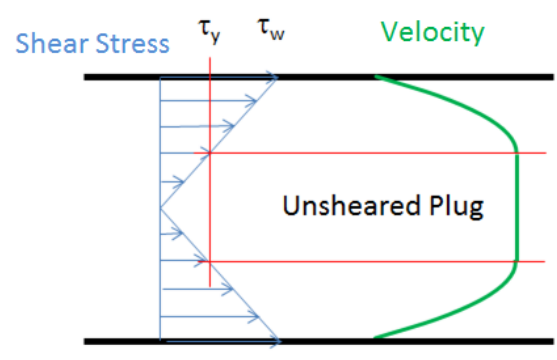

Bingham plastic

\section{LAMINAR CHANNEL FLOW}

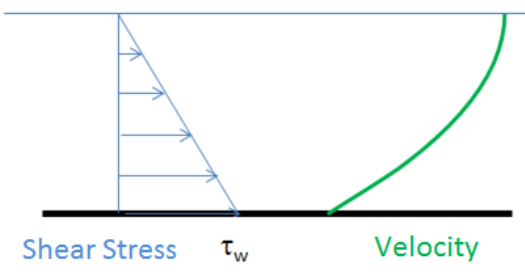

Newtonian fluid

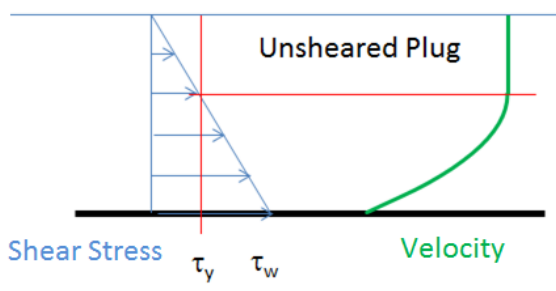

Bingham plastic

Figure 2 Distribution of shear stress and velocity in laminar pipe flow (top) and laminar open channel flow (bottom)

A number of assumptions are proposed for the new open channel plug flow model:

- Flows in the sheared zone are laminar, with parabolic velocity profiles.

- The channel cross section is a half ellipse. 
- The plug is also a half ellipse, with the same width to depth ratio as the greater channel.

\subsection{Slatter's pipe plug flow model}

In his pipe plug flow model, Slatter (1997) proposed that the diameter of the plug in a pipe is equal to:

$$
D_{P}=\left[\frac{\tau_{Y}}{\tau_{W}}\right] D
$$

Where $D_{p}$ is the diameter of the plug, $\tau_{Y}$ is the yield stress of the fluid, $\tau_{W}$ is the wall shear stress in the pipe and $D$ is the internal diameter of the pipe.

At the heart of Slatter's pipe plug flow model was a new Reynolds number, which he called $\mathrm{Re}_{3}$ :

$$
\mathrm{Re}_{3}=\frac{8 \rho V_{\text {ann }}^{2}}{\tau_{Y}+K\left(\frac{8 V_{\text {ann }}}{D_{\text {shear }}}\right)^{n}}
$$

Where $\rho$ is the fluid density $\left(\mathrm{kg} / \mathrm{m}^{3}\right), \mathrm{V}_{\text {ann }}$ is the average velocity in the annulus surrounding the plug core, $\mathrm{K}$ is the consistency index for the Herschel-Bulkley model, $\mathrm{n}$ is the Herschel-Bulkley model power, and $\mathrm{D}_{\text {shear }}$ is the effective diameter of the sheared annulus, where:

$$
D_{\text {shear }}=D-D_{P}
$$

and

$$
V_{a n n}=\frac{Q_{a n n}}{A_{a n n}}
$$

Where $Q_{a n n}$ is the flow rate in the annulus and $A_{a n n}$ is the cross sectional area of the annulus. $Q_{a n n}$ is calculated as follows:

$$
Q_{a n n}=Q-Q_{P}
$$

Where $Q_{p}$ is the flow rate in the plug, equal to:

$$
Q_{P}=u_{P} \cdot A_{P}
$$

With $u_{p}$ as the velocity of the plug and $A_{p}$ as the cross sectional area of the plug. Slatter presented the following equation for determining the plug velocity:

$$
u_{P}=\frac{D}{2 K^{1 / n} \tau_{W}}\left(\frac{n}{n+1}\right)\left[\tau_{W}-\tau_{Y}\right]^{n+1}
$$

\subsection{Adaptation of Slatter's pipe model to suit channels}

For the new open channel plug flow model, Slatter's pipe flow equations must be modified to cater for open channel flow. To calculate the depth of the plug, the following relationship is presented:

$$
d_{P}=\left[\frac{\tau_{Y}}{\tau_{W}}\right] d
$$

Where $d_{p}$ is the depth of the plug at the channel centreline and $d$ is the total depth at the centreline of the channel, as shown in Figure 1.

The $\mathrm{Re}_{3}$ Reynolds number is transformed using the laminar pipe/channel conversion $\mathrm{D}=4 \mathrm{R}_{\mathrm{H}}$ : 


$$
\operatorname{Re}_{3}=\frac{8 \rho V_{S Z}{ }^{2}}{\tau_{Y}+K\left(\frac{2 V_{S Z}}{R_{H S Z}}\right)^{n}}
$$

Where $V_{S Z}$ is the average velocity in the sheared zone and $R_{H S Z}$ is the effective hydraulic radius of the sheared zone. To calculate $R_{H S z}$, the following equation is yielded:

$$
R_{H S Z}=R_{H}-R_{H P}
$$

$R_{H}$ is the hydraulic radius of the channel, and $R_{H P}$ is the hydraulic radius of the plug. $V_{S Z}$ is calculated:

$$
V_{S Z}=\frac{Q_{S Z}}{A_{S Z}}
$$

Where $Q_{s z}$ is the flow rate in the sheared zone and $A_{s z}$ is the cross sectional area of the sheared zone. $Q_{s z}$ is calculated as follows:

$$
Q_{S Z}=Q-Q_{P}
$$

Where $Q_{p}$ is the flow rate in the plug, equal to:

$$
Q_{P}=u_{P} \cdot A_{P}
$$

With $u_{p}$ as the velocity of the plug and $A_{p}$ as the cross sectional area of the plug.

Up to this point the new open channel plug flow model mimics the structure of the Slatter pipe plug flow model, with the constitutive equations of the Slatter model simply modified to suit channels.

Unfortunately though, it was found that Slatter's equation for determining the plug velocity (Equation 7) could not be successfully applied to channel flows after its modification. The $D=4 R_{H}$ conversion equation was applied to replace the $D$ with $R_{H}$, but the resultant equation did not provide sensible answers. It was evident that another solution was required. This problem was addressed by approaching it geometrically as illustrated in Figure 3.

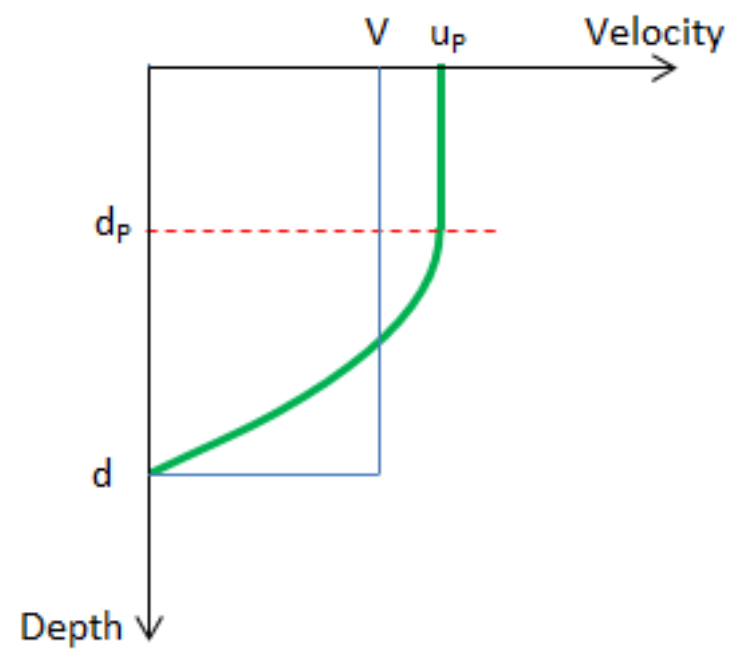

Figure 3 Velocity profiles for a plug flow scenario; the green line shows the actual velocity profile, while the blue line shows the average velocity. The area contained inside both shapes is identical by definition

The two velocity profiles shown in Figure 3 contain the same area. By this paradigm the plug velocity ( $u_{\mathrm{p}}$ ) can be determined by presenting the areas inside the two shapes as follows: 


$$
V . d=u_{P} d_{P}+\frac{2}{3} u_{P}\left(d-d_{P}\right)
$$

Strictly speaking, Equation 14 is only accurate for an infinitely wide channel. We substitute the respective hydraulic radii for the centreline depths to make Equation 14 accurate for our three-dimensional channel. Making up the subject yields:

$$
u_{P}=\frac{V \cdot R_{H}}{R_{H P}+\frac{2}{3}\left(R_{H}-R_{H P}\right)}
$$

The wall shear stress is required for the determination of the plug depth (Equation 8). In channel flow this is typically calculated using DuBoys Equation, but in this particular situation that is not helpful because the channel slope is required as an input parameter, and that is what we are ultimately trying to predict. Instead we have approached the problem by applying with the fundamental relationship between the shear stress $(\tau)$, apparent viscosity $(\eta)$ and shear rate $(\gamma)$ :

$$
\tau=\eta . \propto \&
$$

The shear rates in the channel can be calculated by deriving the quadratic equation for theoretical velocity distribution profile in the sheared zone (note that this parabolic velocity distribution is valid for a Bingham plastic, and will be approximate for a Herschel-Bulkley). The velocity profile can be described as follows:

$$
u=u_{P}-\frac{u_{P}}{\left(d-d_{P}\right)^{2}}\left(\text { depth }-d_{P}\right)^{2}
$$

The derivative of Equation 17 is the shear rate function. Deriving Equation 17 and making the depth equal to the maximum depth $(\mathrm{d})$ yields the shear rate at the channel bed $\left(\gamma_{\mathrm{w}}\right)$ :

$$
\varkappa_{w}=\frac{2 u_{P}}{\left(d-d_{P}\right)}
$$

Substituting the respective hydraulic radii for the centreline depths to make Equation 18 accurate for our three-dimensional channel gives:

$$
\varkappa_{H}=\frac{2 u_{P}}{\left(R_{H}-R_{H P}\right)}
$$

The apparent viscosity is then calculated using the rheological parameters and the shear rate:

$$
\eta=\frac{\tau_{Y}+K . \not \&}{\not \&}
$$

This equation completes the new channel plug flow model. However, it will become immediately evident in the attempted application of this new model that the plug depth is required as an input parameter for determining the wall shear stress, and the wall shear stress is required for calculating the plug depth. Therefore the plug flow model is implicit as presented.

This problem arises from open channel flow possessing an extra dimension over pipe flow in terms of its variable depth, which makes its modelling more complex than that of pipes. An increase in the flow rate in a pipe simply results in an increase in the velocity, for example. In an open channel, an increase in the flow rate will yield an increase in the depth as well as the velocity, particularly where non-Newtonian fluids are involved. As a result of this added variable, an iterative solution is required.

It was found that initially estimating the wall shear stress to be equal to 1.2 times the yield stress enabled a convergent iterative solution to four significant figures to be successfully reached after six iterations. With the use of a computer spreadsheet program, this iterative approach was easily applied. 


\subsection{Channel aspect ratio}

The channel plug flow model presented here thus far will enable the modelling of yield stress fluids in open channels of any cross-sectional geometry.

However, in the case of self-formed tailings channels, there exists the question of the aspect ratio of the channels. Fitton (2007) carried out a numerical analysis of different width-to-depth (w/d) ratios for a limited number of such channels, and after comparing the predicted results against experimentally measured data, recommended 5.5:1. In this present study some effort has been made to back-calculate the width-to-depth ratio $(\mathrm{w} / \mathrm{d})$ for each of the self-formed channels that were observed in a series of flume experiments that were recently carried out at the Chuquicamata copper mine by ATC Williams (Pirouz et al., 2013).

It was not possible to measure the depth of the self-formed channels during that experimental work, since any disturbance to the channel created by the immersion of a probe would result in the destruction of the fragile channel bed and banks. However, flow rates, plug velocities and channel widths were measured, so it was possible to back-calculate the channel depth. This deduction of channel depths was undertaken, and it was found that the aspect ratios for the 17 measured self-formed channels varied from 2.5 to 11 .

Due to the considerable spread of aspect ratios that were thus calculated for the Chuquicamata flume trials, it was decided that the new plug flow model should include an aspect ratio prediction model if any reasonably strong trends could be discovered between the deduced aspect ratio and some of the measureable characteristics of the slurry, rather than simply assuming a constant ratio.

Analysis was carried out to identify trends relating the slurry characteristics to the width-to-depth ratios calculated for the Chuquicamata data. It was found that a modest trend was observed when the $\mathrm{w} / \mathrm{d}$ values were plotted against the Bingham yield stress of the slurry. This plot is presented as Figure 4 . It is noted that the Bingham fit to each rheogram was tangent to the $100 \mathrm{~s}^{-1}$ point on the curve. 


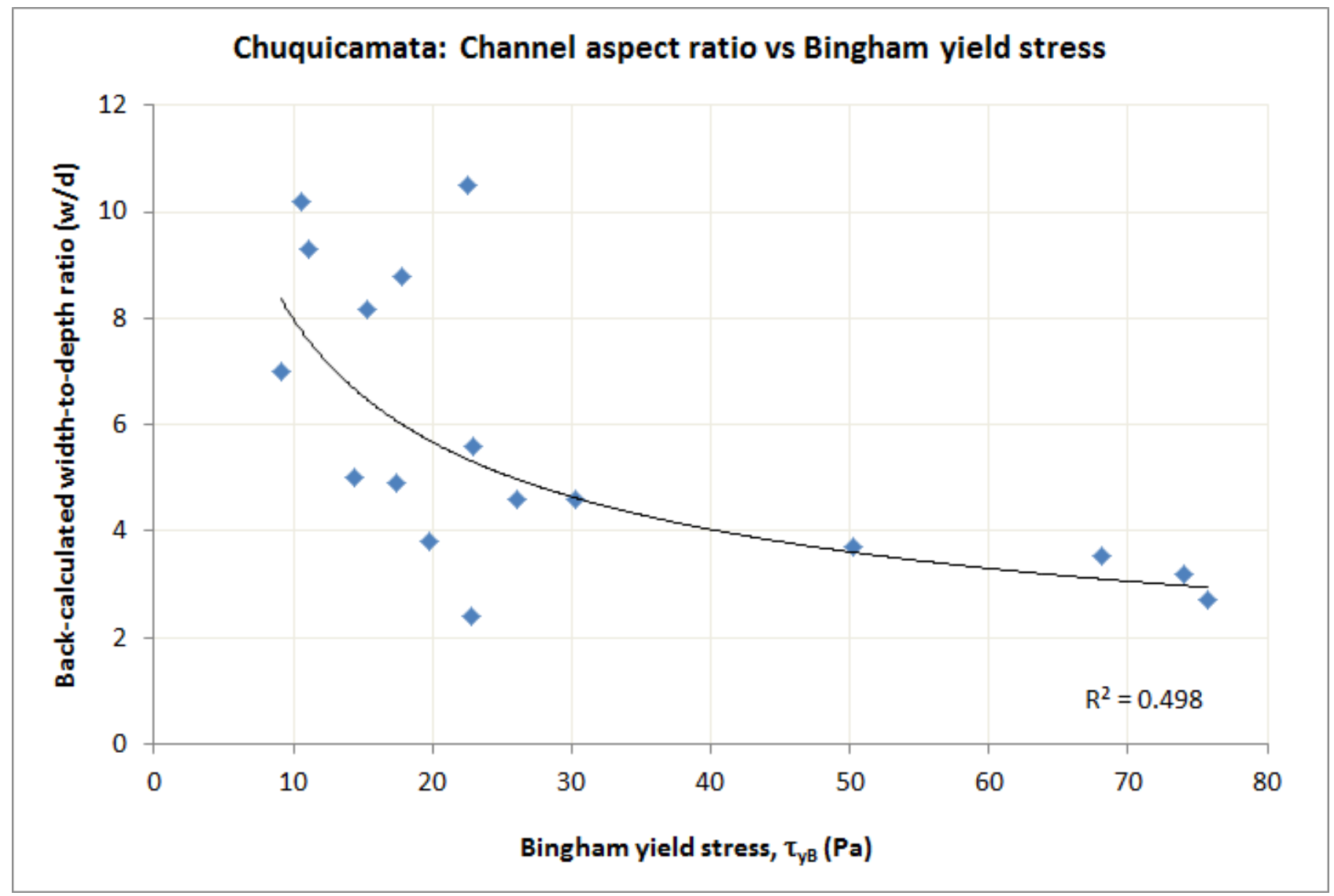

Figure 4 Plot of Bingham yield stress versus w/d ratio for the self-formed channels in the Chuquicamata flume trials

The equation describing the trend curve that is shown on the Figure 4 plot is as follows:

$$
w / d=\frac{25}{\sqrt{\tau_{y B}}}
$$

This equation was adopted for predicting channel aspect ratios for self-formed channels in the new plug flow model.

\subsection{Elliptical geometric equations}

In order to apply the plug flow channel model to an elliptical channel shape it is necessary to calculate the cross sectional area and the wetted perimeter of a half ellipse such as that shown in Figure 1. The following equation can be used to calculate the area of the half ellipse:

$$
A=\frac{\pi d w}{4}
$$

Ramanujan (1914) presented an excellent approximation for calculating the circumference of an ellipse. It has been modified here for calculating the wetted perimeter of the half ellipse:

$$
P=\frac{\pi}{2}(w / 2+d) \cdot\left[1+\frac{3\left(\frac{w / 2-d}{w / 2+d}\right)^{2}}{10+\sqrt{4-3\left(\frac{w / 2-d}{w / 2+d}\right)^{2}}}\right]
$$


It is noted that Equations 22 and 23 can also be used to calculate the area and wetted perimeter of the plug $\left(A_{p}\right.$ and $\left.P_{P}\right)$ if the plug depth and plug width are used instead of the overall channel depth and width respectively.

\section{A new beach slope model incorporating the plug flow model}

A new beach slope model is presented that incorporates the plug flow model described above. The overall approach is similar to the a priori beach slope model previously presented by Fitton (2007), but the plug flow model adds some more steps to the process. The mechanism at the heart of the new plug flow beach slope model remains the same - the channel depth is adjusted until the channel velocity is equal to the predicted minimum transport velocity. At this point the channel slope is calculated.

For non-segregating slurries, Fitton (2007) proposed a minimum transport velocity equation, based on experimental correlations of the critical velocity and the Reynolds number for a Bingham plastic observed in flow-through flume tests:

$$
V_{C N S}=0.145 \ln \left(\frac{\rho V R_{H}}{K_{B}}\right)
$$

Where the $V_{C N S}$ is the minimum transport velocity for a non-segregating slurry and $K_{B}$ is the Bingham plastic viscosity. This minimum transport velocity equation is recommended for use in the new plug flow beach slope model.

\subsection{Input data}

To apply the new plug flow beach slope model, the following input parameters are required:

- Flow rate at each discharge point, $Q\left(\mathrm{~m}^{3} / \mathrm{s}\right)$.

- Slurry concentration, $\mathrm{C}_{\mathrm{w}}(\% \mathrm{w} / \mathrm{w})$.

- Specific gravity of solids, $\rho_{\mathrm{s}}\left(\mathrm{kg} / \mathrm{m}^{3}\right)$.

- Specific gravity of slurry water, $\rho_{\mathrm{w}}\left(\mathrm{kg} / \mathrm{m}^{3}\right)$.

- A rheogram for the discharged concentration of slurry.

It is assumed that the slurry is non-segregating. For this reason, particle size data is not relevant to the new model, and is not required. It is further noted that flume tests are not needed to make a beach slope prediction with this model, nor are large samples of slurry required.

\subsection{Beach slope prediction sequence}

The slope prediction sequence is as follows:

1. Assume a depth of channel, $d$.

2. Calculate the $w / d$ aspect ratio using Equation 21.

3. Calculate $V=Q / A$, where $A$ is the cross sectional area of the channel.

4. Calculate $R_{h}=\mathrm{A} / \mathrm{P}$, where $\mathrm{P}$ is the wetted perimeter of the channel.

5. Compute $V_{C N S}$ using Equation 24. Repeat 1 through 5 until $V=V_{c}$.

6. Calculate the plug depth using Equation 8 , initially assuming $\tau_{\mathrm{W}}=1.2 \tau_{\mathrm{\gamma}}$.

7. Using the same $w / d$ aspect ratio calculated in Step 2, compute $A_{P}, P_{P}$ and $R_{H P}$.

8. Calculate $R_{H S Z}$ using Equation 10.

9. Calculate up using Equation 15. 
10. Calculate $Q_{p}, Q_{s z}$ and $V_{s z}$ using Equations 13,12 and 11 respectively.

11. Calculate the wall shear rate with Equation 19, using $R_{H P}$ from Step 7 and $u_{P}$ from Step 9.

12. Calculate $\eta$ and $\tau_{w}$ using Equations 20 and 16 respectively.

13. Now recalculate the plug depth with Equation 8, using the $\tau_{\mathrm{w}}$ gained in Step 12.

14. Repeat Steps 7 to 13 several times until convergent $V_{S Z}$ and $R_{H S Z}$ values are reached.

15. Determine Re3 using Equation 9.

16. Calculate the Darcy friction factor $f$ using the Hagen-Poiseuille Equation, $f=64 / R e$.

17. The slope for uniform flow in the channel is then calculated using the Darcy-Weisbach Equation:

$$
S_{0}=\frac{V^{2} f}{8 g R_{H}}
$$

$S_{o}$ is taken to be the beach slope, though it is noted that a rational approach should be made to estimate the likely variation that will occur in the tailings production rate and thickener underflow concentration. This should in turn be used to predict a beach profile (which will be concave). A method for carrying out such work has been presented in Seddon and Fitton (2011).

\section{$4 \quad$ Validation of the new plug flow beach slope model}

The plug flow beach slope prediction method was compared to three separate sets of experimental data collected in $10 \mathrm{~m}$ long flow-through flumes, as well as an independent set of full-scale tailings beach slope data from ATC Williams, covering 29 real beach slopes. Some details of the flume experiments are presented in Table 1.

The overall performance against the experimental and full-scale beach data is given in Figure 5 .

Table 1 Summary of key parameters for experimental flume data

\begin{tabular}{cccc}
\hline Experimental measurement & Peak (Cobar) & Sunrise Dam & Chuquicamata \\
\hline No. of equilibrium slopes recorded & 9 & 41 & 32 \\
Steepest equilibrium slope (\%) & 3.7 & 6.0 & 9.8 \\
Flattest equilibrium slope (\%) & 1.7 & 0.75 & 4.6 \\
Maximum flow rate (I/s) & 19 & 24 & 18.1 \\
Minimum flow rate (I/s) & 1.9 & 1.9 & 5.5 \\
Maximum concentration (\% w/w) & 57.7 & 66.8 & 72.8 \\
Minimum concentration (\% w/w) & 45.8 & 25.8 & 56.1 \\
Solids SG & 2.8 & 2.8 & 2.75 \\
Segregation threshold (\% w/w) & $\sim 46$ & $\sim 52$ & $\sim 50$ \\
Herschel-Bulkley rheological fit for slurry at maximum concentration: & \\
Yield strength, $\tau_{y}$ (Pa) & 3.65 & 21.2 & 33.2 \\
Fluid consistency index, $K$ & 0.076 & 0.44 & 10.3 \\
(Pa.s) & 0.81 & 0.60 & 0.43 \\
Flow behaviour index, $n$ & 0.016 & 0.030 & 0.321 \\
\hline
\end{tabular}




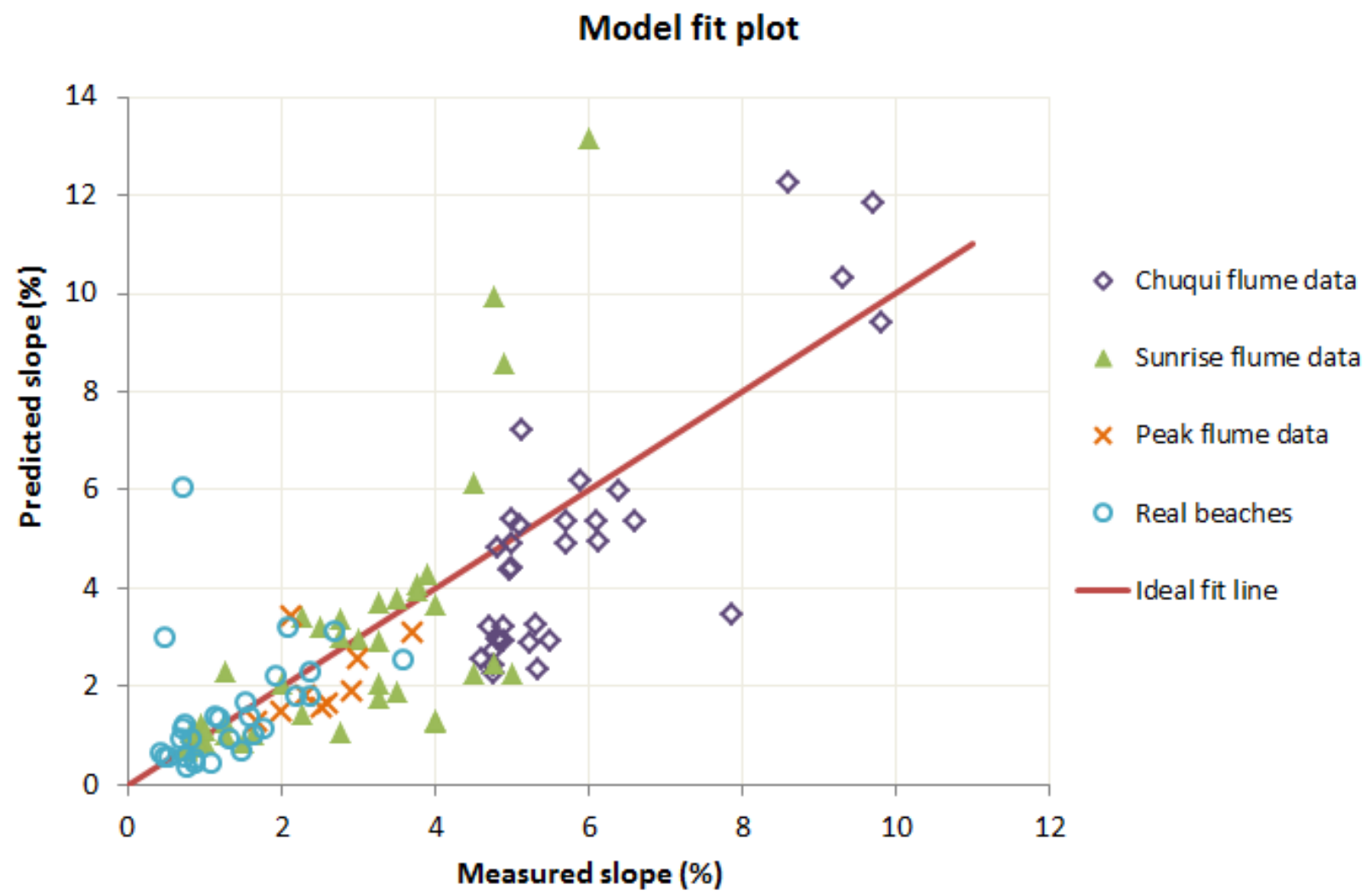
Figure 5 Fit plot showing the predictive performance of the new plug flow beach slope
model

\section{Discussion}

In this paper a new plug flow beach slope model has been presented, at the heart of which is a new channel plug flow model. It is believed that this plug flow model for open channels is the first of its kind to be published. The impetus for the creation of such a model arises from pressure applied by the mining industry to recover more water from tailings. Where paste thickeners are being installed on such sites for the recovery of water, the resultant tailings slurries are thickened well above the segregation threshold of the slurry, with high yield stresses that result in plug flow occurring in the self-formed channels on the tailings beaches. It is apparent that such viscous slurries are not subject to the turbulent mechanisms of the sediment transport approach that has been successfully incorporated into beach slope models for less concentrated slurries in the past (Fitton, 2007; Thomas and Fitton, 2011).

The predictive performance of this new plug flow beach slope model is reasonably good, with $86 \%$ of the predictions falling between $0.5 \mathrm{~S}$ and $2.0 \mathrm{~S}$ (where $\mathrm{S}$ is the observed slope) and $43 \%$ of predictions falling between $0.8 \mathrm{~S}$ and $1.25 \mathrm{~S}$. It is conceded that this leaves plenty of room for improvement, particularly for the $14 \%$ of points that were poorly predicted.

One issue that deserves some discussion here is the settlement of particles that always occurs in laminar flows (Pullum et al., 2006). This issue is usually raised in the context of slurry pipeline design, where laminar flows are generally avoided because of the resultant deposition of particles on the pipe invert over time. Historically it has been claimed that a tailings channel on a beach must be turbulent, so that the tailings slurry is transported along the beach to its deposition point (Pirouz et al., 2005; Chryss et al., 2006; Fitton et al., 2006).

The work presented here shows that if the slurry is thick enough or the flow rate small enough, a laminar flowing channel is produced. Indeed the flume trials carried out at the Chuquicamata copper mine further confirmed this, with Reynolds numbers ranging from 100 to 1,400 for all 32 of the equilibrium slopes measured in the flume. At Sunrise Dam a few laminar flows were also recorded in the flume when it was 
running higher concentrations at low flow rates. This finding leads to the questioning of how tailings transport can be maintained in laminar channels on a tailings beach. The following explanation is postulated: on a tailings beach a laminar flowing channel can serve to transport the vast majority of particles to the outer reaches. The channel will rise over time as a small amount of solids settle on the bed, causing it to build its own banks slightly higher and higher due to the settling and yield stress increase of slow moving slurry at the channel edges. Small amounts of spillage occur at the edges of the channel periodically, but the sides of the channel have an ability to 'self-heal', due to this same settling / yield stress increase of the fluid that is subject to the low shear rates experienced at the channel edges. Plenty of this self-healing behaviour was observed during the self-formed flume flows at Chuquicamata.

Eventually though, due to the deposition of tailings at the distal end of the channel constantly presenting a greater amount of flow resistance further upstream in the channel, the channel will breach one of its banks and adopt a new direction. This periodic re-routing of channels means that they are not required to flow for much more than a few days. It is therefore very possible for laminar flow to serve as a viable transport medium for the vast majority of the tailings. Such channels still serve to provide effective total transport, even though they are technically not actually transporting all of the solids. In the context of a tailings beach, where the channel route is transient, laminar deposition becomes negligible and essentially irrelevant.

\section{Conclusions}

A new tailings beach slope model has been presented for predicting the beach slopes that are formed by the hydraulic discharge of tailings slurry that exhibits plug flow. Upon comparison with flume data and real tailings beach slope data the beach slope model is shown to predict beach slopes reasonably well. A new open channel plug flow model has also been presented, which forms the heart of the beach slope model. This work has also shown that the self-formed channels flowing on a tailings beach can be laminar, and that viscoplastic behaviour can be accommodated.

\section{Acknowledgement}

The authors wish to thank Codelco for permission to publish information relating to the flume trials.

\section{References}

Chryss, A.G., Fitton, T.G. and Bhattacharya, S.N. (2006) Turbulent flow of non-Newtonian tailings in self-formed channels on tailings stacks, in Proceedings Ninth International Seminar on Paste and Thickened Tailings (Paste06), R.J. Jewell, S. Lawson and P. Newman (eds), 3-7 April 2006, Limerick, Ireland, Australian Centre for Geomechanics, Perth, pp. 429-438.

Fitton, T.G., Chryss, A.G. and Bhattacharya, S.N. (2006) Tailings beach slope prediction: a new rheological method, International Journal of Surface Mining, Reclamation and Environment, Vol. 20, No. 3, pp. 181-202.

Fitton, T.G. (2007) Tailings beach slope prediction, PhD thesis, RMIT University, Australia (since published as a book by VDM Verlag, Saarbrücken, Germany in 2010).

Melent'ev, B.A., Kolpashnikov, H.P. and Volnin, B.A. (1973) Alluvial hydraulically engineered constructions, Energy, Moscow.

Pirouz, B., Kavianpour, M.R. and Williams, M.P.A. (2005) Thickened tailings beach deposition - field observations and full-scale flume testing, in Proceedings Eighth International Seminar on Paste and Thickened Tailings (Paste05), R.J. Jewell and S. Barrera (eds), 20-22 April 2005, Santiago, Chile, Australian Centre for Geomechanics, Perth, pp. 53-72.

Pirouz, B., Seddon, K.D., Williams, M.P.A., Echevarria, J. and Pavissich, C. (2013) Flow through tilt flume testing for beach slope evaluation at Chuquicamata Mine Codelco, Chile, in Proceedings 16th International Seminar on Paste and Thickened Tailings (Paste 2013), 17-20 June 2013, Belo Horizonte, Brazil, Australian Centre for Geomechanics, Perth, pp. 459-474.

Pullum, L., Graham, L., Rudman, M., Aldham, B. and Hamilton, R. (2006) The ups and downs of paste transport, in Proceedings Ninth International Seminar on Paste and Thickened Tailings (Paste06), R.J. Jewell, S. Lawson and P. Newman (eds), 3-7 April 2006, Limerick, Ireland, Australian Centre for Geomechanics, Perth, pp. 395-402.

Ramanujan, S. (1914) Modular equations and approximations to Pi, The Quarterly Journal of Pure and Applied Mathematics, Vol. 45 (1913-1914), pp. 350-372.

Seddon, K.D. and Fitton, T.G. (2011) Realistic beach slope prediction and design, in Proceedings 14th International Seminar on Paste and Thickened Tailings (Paste2011), R.J. Jewell and A.B. Fourie (eds), 5-7 April 2011, Perth, Australia, Australian Centre for Geomechanics, Perth, pp. 281-294.

Slatter, P.T. (1997) The effect of the yield stress on the laminar/turbulent transition, in Proceedings 9th International Conference on Transport and Sedimentation of Solid Particles, 2-5 September 1997, Crakow, Poland. 
Thomas, A.D. and Fitton, T.G. (2011) Analysis of tailings beach slopes based on slurry pipeline experience, in Proceedings 14th International Seminar on Paste and Thickened Tailings (Paste2011), R.J. Jewell and A.B. Fourie (eds), 5-7 April 2011, Perth, Australia, Australian Centre for Geomechanics, Perth, pp. 295-306.

Williams, M.P.A. and Meynink, W.J.C. (1986) Tailings beach slopes, paper presented to Workshop on Mine Tailings Disposal, The University of Queensland. 
